\title{
Length Scale of the Dendritic Array Tailoring Strength of a 5052 Aluminum Alloy
}

\author{
Cínthia Toshimi Ogata ${ }^{a}$, Rodrigo Valenzuela Reyes ${ }^{a}$, Amauri Garcia ${ }^{b}$, José Eduardo Spinelli ${ }^{a *}$ (D)
}

\author{
${ }^{a}$ Departamento de Engenharia de Materiais, Universidade Federal de São Carlos (UFSCar), $13565-$ \\ 905, São Carlos, SP, Brasil \\ ${ }^{b}$ Departamento de Engenharia de Manufatura e Materiais, Universidade de Campinas (UNICAMP), \\ 13083-860, Campinas, SP, Brasil
}

Received: August 08, 2018; Revised: September 29, 2018; Accepted: October 25, 2018

\begin{abstract}
The present research aims to characterize $5 \mathrm{xxx}$ alloy series, considering chemistries based on the commercial 5052 alloy with three $\mathrm{Mg}$ contents (2.4wt.\%, 2.6wt.\% and 3.2wt.\%) through transient directional solidification experiments. Very representative incoming impurities to a given twin-roll casting procedure were reached. As such, the $\mathrm{Si}, \mathrm{Fe}, \mathrm{Cu}, \mathrm{Mn}$ and $\mathrm{Cr}$-contents in the tested samples typically trend in between the suitable alloying spectrum. Microstructural analyzes were performed using polarized light microscopy of samples taken from various ingot positions. Growth relationships between the secondary dendritic spacing $\left(\lambda_{2}\right)$ and the growth velocity were determined. The 5052 alloys containing higher $\mathrm{Mg}$ content may induce a decrease in $\lambda_{2}$ for a certain growth velocity. The hardness values measured across the three directionally solidified castings were directly related to the $\lambda$, which can be considered a fundamental variable affecting mechanical strength. For representative conditions vis-à-vis those employed in industry, it was shown that even relatively small changes in $\mathrm{Mg}$ content of the 5052 alloy may have some impact on $\lambda_{2}$. These results open new ways to predict the final as-cast microstructure characterizing commercial 5052 alloy products, with a view to controlling not only the dendritic growth but also the $\mathrm{Mg}$ content during casting operations.
\end{abstract}

Keywords: AA5052, Directional Solidification, Microstructure, Intermetallics, Hardness.

\section{Introduction}

High strength, high corrosion resistance, fair to good weldability are some characteristics related to the 5052 alloys ${ }^{1-3}$. These characteristics explain why these alloys have been broadly utilized in industries such as transportation and marine. Among several examples of applications, one can highlight parts as shutters, boats, signs, automobile bodies and stamping for general use ${ }^{4}$. Considering forming and welding processes using the 5052 alloy, it can be verified that resulting properties and microstructures were extensively studied and correlated to each other ${ }^{5-8}$. However, dendritic arrangement, morphology and dimensions of the primary $\alpha-\mathrm{Al}$ phase and their relationships to mechanical strength are not fully assessed to date. This is especially unnoticed if continuous and transient casting processes with the 5052 alloy are considered, as for example the twin roll casting (TRC).

The TRC process can be used to produce Al-Mg sheet from $\sim 10.0$ to $\sim 0.5 \mathrm{~mm}$ thick directly from the melt ${ }^{9}$. Due to the nature of this process, coarser microstructures were observed when moving from the surface in contact with the roll to the center line of the casting, that is, dimensions typifying the as-cast microstructure will vary across the sheet thickness. In any case, a sheet will be produced considering some variations in the length-scale of the microstructure across the product. This can be more significant if thicker products are considered under process, e.g., direct chill (DC) casting operations. The range of operational conditions limiting such variations include melt temperature superheat, mold material, mold roughness, alloy chemistry, among others. Considering the transient heat flow regime of the continuous casting processes, the cooling down regime achieved during water-cooled transient directional solidification of Al-based alloys can be considered compatible ${ }^{10,11}$, despite being slightly slower when the cooling regimes are compared.

When examining the $\mathrm{Mg}$-content typically accepted in the 5052 alloys, distinct alloyed levels were documented. For example, Rodrigues and co-authors stated that the 5052 alloy containing $3.15 \mathrm{wt} . \% \mathrm{Mg}$ is used for commercial purposes. On the other hand, according to the ASTM B209M standard ${ }^{12}$ the $\mathrm{Mg}$ content may vary between 2.2 and 2.8 wt.\%. Another compositional characteristic is related to the presence of some impurities in the alloy, especially $\mathrm{Si}, \mathrm{Fe}$ and $\mathrm{Cr}$. Bearing in mind that such relative important spectrum of $\mathrm{Mg}$ alloying is current in the commercial applications it appears very required to perform an investigation about the effects of alloy $\mathrm{Mg}$ content on the final characteristics of the as-cast 5052 alloy. Such features at this stage of Al-Mg products are mainly related to the dendritic growth in metallic alloys. Various investigations demonstrated that the dendritic microstructure plays a notable role in porosity distribution, mechanical properties, corrosion and wear properties of foundry and cast products ${ }^{13-15}$. 
To the best of our knowledge insufficient data exists to make a thorough comparison between lower and higher Mg-content 5052 alloys from a microstructural viewpoint. It is well known that the microstructural scales of dendrites, translated by the secondary arm spacings, control the segregation profiles and the distribution of secondary phases within interdendritic regions. Consequently, such dimensional parameter is usually considered very effective in changing the properties of Al-based as-cast products.

Considering studies employing directional solidification as a method, a sole investigation concerning the 5052 alloy has been identified so far. The effects of three temperature melt superheats $(10 \%, 15 \%$ and $20 \%)$ on both kinetics of solidification and microstructure for an alloy containing $3.1 \mathrm{wt}$. $\% \mathrm{Mg}$ were examined ${ }^{16}$. It was demonstrated that the lower the melt superheat, the higher is the growth velocity. Furthermore, it was observed that the secondary dendrite arm spacing, $\lambda_{2}$, increases with increasing the superheating level, being $\lambda_{2}$ much lower in average for the temperature superheat of $10 \%$ above the liquidus temperature of the alloy.

Other research works dealing with $\mathrm{Al}-\mathrm{Mg}$ alloys may be cited in the present context. For example, Gomes et al. ${ }^{17}$ investigated the dendritic morphology and tensile properties of the Al-1.2 wt pet Mg-1.5 wt pet Fe and Al-7 wt pet Mg-1.5 wt pet Fe alloys. Experimental plots of secondary dendrite arm spacings with cooling rate and of tensile properties with $\lambda_{2}$ were proposed. It was demonstrated that Hall-Petch type formulas could be representative of the variations of the mechanical strength with $\lambda_{2}$. Practical inter-relations regarding tensile properties with cooling rates were outlined. Brito et al. ${ }^{18}$ investigated the ternary Al-3 wt $\% \mathrm{Mg}-1 \mathrm{wt} \% \mathrm{Si}$ alloy by transient unidirectional solidification. It was demonstrated the development of a reverse cell-to-dendrite transition with cells growing for cooling rates higher than $2 \mathrm{~K} / \mathrm{s}$. Plots of the cellular and the dendritic spacings with the cooling rate were shown.

The present research work aims to gain insight into the effects of $\mathrm{Mg}$ content on the dendritic growth and hardness of the commercial 5052 aluminum alloys. The chosen chemistries take into account possible variations in $\mathrm{Mg}$ content inside the alloy spectrum of $\mathrm{Mg}$. As such, transient directional solidification experiments were carried out with three commercial 5052 alloys containing 2.4wt.\%, 2.6wt.\% and 3.2wt.\% Mg. Firstly, the growth of dendrites was typified by secondary dendritic spacing, $\lambda_{2}$, measurements for the three compositions. All alloys were solidified under broad ranges of growth velocities and local solidification times. Secondly, variations of $\lambda_{2}$ with growth velocity were established. Lastly, the present study outlines the correlations between the local length scale of the microstructure, that is, $\lambda_{2}$, and hardness.

\section{Experimental procedure}

\subsection{Solidification experiment}

The 5052 alloys castings were generated using a transient directional solidification system. The compositions of these alloys are shown in Table 1.

The optical emission spectrometry method permitted the stated average compositions in Table 1 to be determined. This method - by using an equipment model 3460 from Applied Research Laboratories - involved statistical processing of the spark pulse-generated emission spectra obtained from spark discharges in an argon atmosphere for 10 specimens of each alloy. These results confirm the nominal Mg contents aimed in this research. An additional point reveals that all the three compositions achieved the level of impurities ( $\mathrm{Si}$, $\mathrm{Fe}, \mathrm{Cu}, \mathrm{Mn}, \mathrm{Cr}$ ) that must be already present in industrial continuous casting products as required under the standards 19

Detailed descriptions of the directional solidification process and of extraction of samples for metallography and mechanical tests are given elsewhere ${ }^{20,21}$.

Liquidus and solidus temperatures were determined for the three 5052 based alloys through experiments in which the alloy was slowly cooled in a well-insulated crucible, thus permitting the transformation temperatures to be determined, as illustrated in Fig. 1.

The 5052 alloys were firstly melted in an induction furnace. Later than, the molten alloy was poured into two cavities, that is, either a crucible dedicated to the cooling curves or a split mold inserted into the solidification system. A remelting operation of the alloy was run inside the mold since radial electrical wiring heated up the cylindrical stainless steel split mold (see Fig. 1). When the melt temperature achieved 5\% above the liquidus temperature, the furnace windings were disconnected and the same time the external water flow at the bottom of the container was to begin the cooling down procedure, thus permitting the onset of solidification.

The solidification system permits the placing of a number of fine K-type thermocouples along the length of the casting. Eight (8) thermocouples were strategically spaced between each other until $98 \mathrm{~mm}$ from the cooled bottom of the casting. The frequency of temperature data acquisition was $5 \mathrm{~Hz}$ on each thermocouple. Postmortem examination regarding the determination of exact positions of the thermocouple tips was carried out.

Considering that the liquidus transformation temperatures were determined through thermal analysis in well-insulated crucibles before the alloys being subjected to directional solidification, data of the thermal profiles through directional solidification have been used to determine the velocity of the liquidus isotherm (i.e., the growth velocity), the cooling rate and the local solidification times as will be seen later. 
Table 1. Chemical composition (wt \%) of the tested 5052 alloys varying the $\mathrm{Mg}$ content.

\begin{tabular}{lccccccc}
\hline Alloy & $\mathrm{Si}$ & $\mathrm{Fe}$ & $\mathrm{Cu}$ & $\mathrm{Mn}$ & $\mathrm{Mg}$ & $\mathrm{Cr}$ & $\mathrm{Al}$ \\
\hline $5052-2.4 w t . \% \mathrm{Mg} *$ & 0.106 & 0.274 & 0.004 & 0.040 & 2.441 & 0.198 & Balance \\
$5052-2.6 w t . \% \mathrm{Mg} *$ & 0.103 & 0.273 & 0.019 & 0.042 & 2.649 & 0.201 & Balance \\
$5052-3.2 w t . \% \mathrm{Mg} *$ & 0.112 & 0.282 & 0.010 & 0.044 & 3.224 & 0.210 & Balance \\
\hline
\end{tabular}

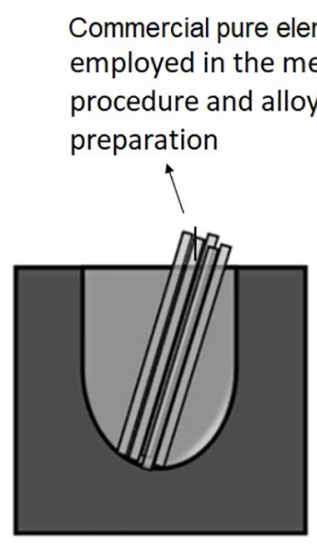

induction furnace

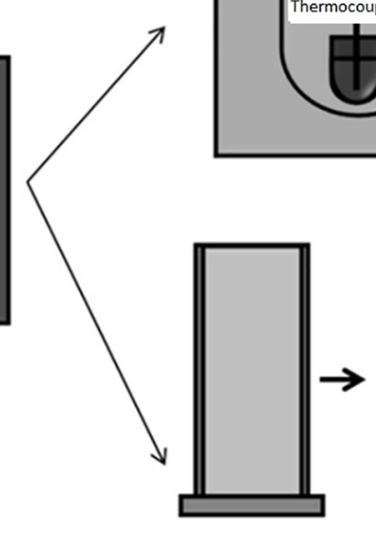

Directional solidification setup

\section{Monitored}

slow cooling

curves to determine eutecticand liquidus temperatures
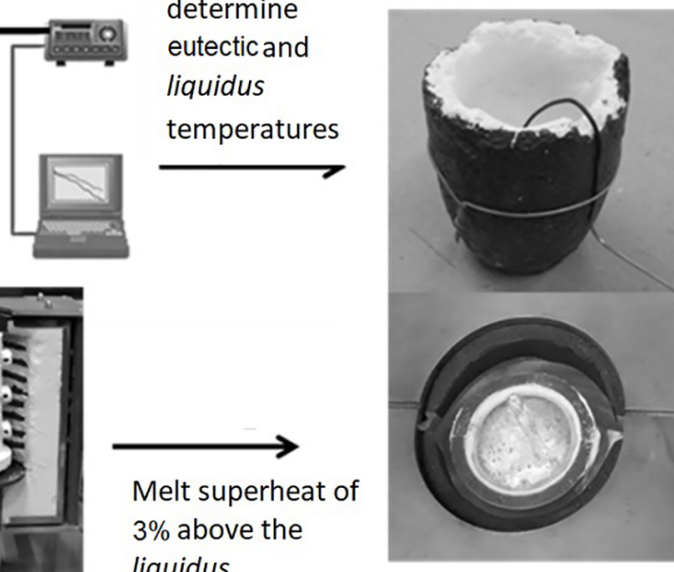

Melt superheat of $3 \%$ above the liquidus

temperature

Figure 1. Overall sketches showing two adopted techniques dealing with the molten 5052 aluminum alloy in the present research, which are: (a) determination of cooling curves and conquently liquidus temperatures and (b) assembly of the directional solidification system with insertion of thermocouples within a split stainless steel mold.

\subsection{Microstructural characterization and hardness tests}

The macrostructure of each directionally solidified (DS) casting was revealed after assessing and grinding the whole longitudinal middle section surface with \#600 grid paper. The etching solution for that was $200 \mathrm{~m} l$ of distilled water, $200 \mathrm{~m} l$ of $\mathrm{HCl}, 200 \mathrm{~m} l$ of $\mathrm{HNO}_{3}$ and $20 \mathrm{~m} l$ of $\mathrm{HF}$, which was applied for a couple of minutes.

Longitudinal samples of various positions from the cooled bottom of the DS castings were mounted (i.e., $5 \mathrm{~mm}, 10 \mathrm{~mm}$, $15 \mathrm{~mm}, 20 \mathrm{~mm}, 25 \mathrm{~mm}, 30 \mathrm{~mm}, 40 \mathrm{~mm}, 50 \mathrm{~mm}$ and $70 \mathrm{~mm}$ ), polished and etched with a solution of $0.5 \%$ HF in water during $20 \mathrm{~s}$, and then examined using an optical microscope. The 5052-3.2wt.\%Mg alloy casting revealed the formation of feathery grains together with columnar ones. Considering the prevalence of columnar grains constituting the other two examined alloys, a less pronounced columnar zone until $40 \mathrm{~mm}$ from the casting basis (left side of the macrostructure picture) was considered in the case of the 5052-3.2wt.\%Mg alloy. Also, the same zone length was considered for the hardness profile as will be confirmed later.

For better visualization of the grains and especially of the secondary dendritic branches a simple technique of illumination of the samples with polarized light was employed. The optical anisotropic character of the formed microstructures enhances the possibilities of visualization by a polarized light microscope. As such, the images were acquired through the instrument Olympus BX51M with a lens type U-TAD together with the usage of the software OLYMPUS Stream Essentials ${ }^{\circledR}$. The preparation of the samples used a DC power supply in combination with a magnetic stirrer. Thus, the samples were immersed in a $1.8 \% \mathrm{HBF}$ solution in water under stirring at $0.2 \mathrm{~V}$ for 3 minutes. The length-scale of the dendritic matrix was characterized by the secondary dendritic arm spacings.

Measurements on the as-solidified microstructure were performed using the line intercept method ${ }^{22}$ for the secondary dendritic arm spacing, $\lambda_{2}$. Forty - 40- measurements were performed for each selected position of a certain alloy composition.

Brinell hardness profiles along the length of each alloy casting were determined by using a $31.25 \mathrm{kgf}$ test force, a $2.5 \mathrm{~mm}$ diameter carbide ball and a dwell time of $10 \mathrm{~s}$. The adopted Brinell hardnesses were the average of at least 10 measurements on each specimen. 


\section{Results and discussion}

\subsection{Macrostructure and solute distribution}

The resultant directional solidified macrostructures are shown in Fig. 2. The basic feature of the formed grains as shown by these macrostructures is that the columnar growth prevails. This is explained by the elevated heat transfer efficiency provided by the water-cooled mold at the bottom of the system. In order to avoid the non-aligned zone of

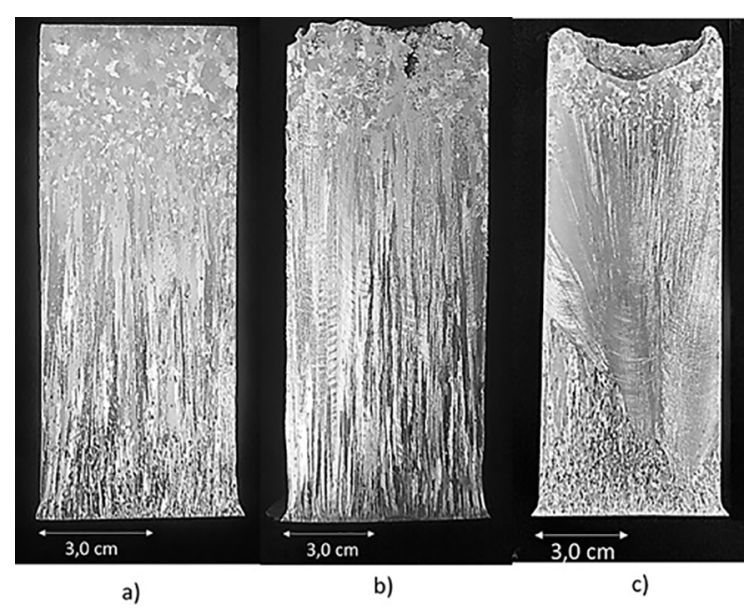

Figure 2. Structures of grains characterizing the directionally solidified (a) $5052-2.4 \mathrm{wt} \% \mathrm{Mg}$, (b) $5052-2.6 \mathrm{wt} \% \mathrm{Mg}$ and (c) 5052-3.2 $\mathrm{wt} \% \mathrm{Mg}$ alloys castings.

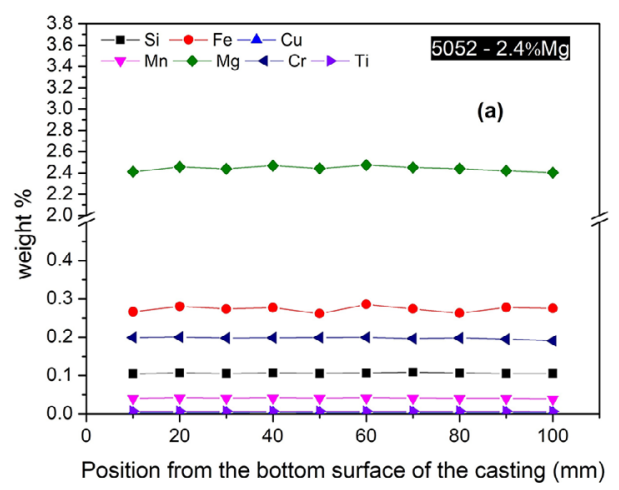

grains in the 5052-3.2wt.\%Mg alloy (Fig. 2c), a zone with vertically aligned grains was chosen to be examined in the subsequent microstructural examination. Thus, the analysis of feathery grains has been avoided since it remains out of the scope of this study.

The results provided by the optical emission spectrometry demonstrated that contents of $\mathrm{Mg}$ and other elements may be considered essentially constants for various positions along the length of the castings, as can be seen in Fig. 3. In all cases the chemistries rest inside the alloying spectrum accepted for the commercial 5052 aluminum alloy. It is also important to emphasize that due the preservation of the composition along each alloy casting, effects resulting from composition variation do not exist for any of the examined alloys.

\subsection{Microstructure and solidification thermal variables}

Fig. 4 shows the isopleth simulation relative to the Al$0.3 w \mathrm{w} \% \mathrm{Fe}-0.1 \mathrm{wt} \% \mathrm{Si}-\mathrm{xwt} \% \mathrm{Mg}$ system as computed by the Thermo-Calc software. The three compositions of interest were signed in the diagram to facilitate the interpretation. The following precipitations may occur for the 5052 alloys: $\alpha$-Al, followed by the growth of Fe-bearing intermetallic particles and, after that, the growth of $\mathrm{Mg}_{2} \mathrm{Si}$.

As-cast microstructures have been fully assessed across the DS parties. As such, it has been possible to investigate the effects caused by different $\mathrm{Mg}$ contents within the specification of a commercial 5052 aluminum alloy on the
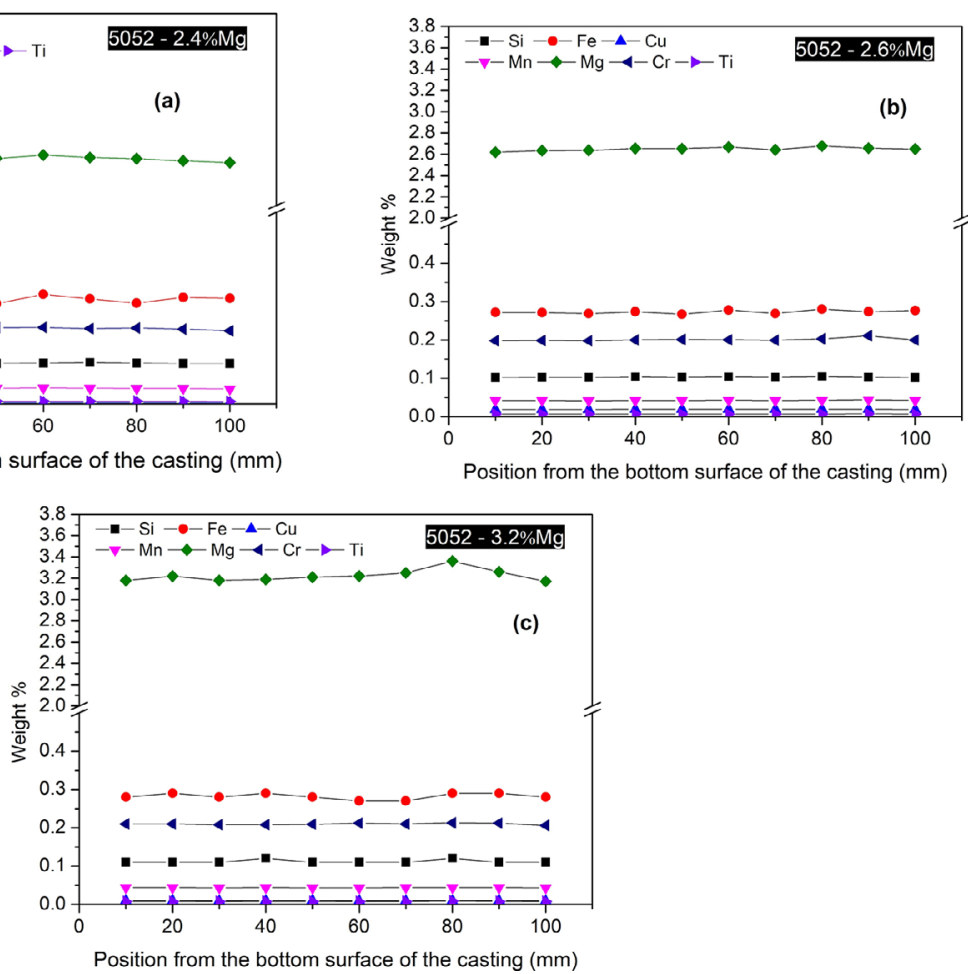

Figure 3. Experimental concentration profiles including $\mathrm{Mg}$ and impurities for the (a) $5052-2.4 \mathrm{wt} \% \mathrm{Mg}$, (b) $5052-2.6 \mathrm{wt} \% \mathrm{Mg}$ and (c) $5052-3.2 \mathrm{wt} \% \mathrm{Mg}$ alloys. 
dendritic array, which appears to be quite essential. Fig. 5 shows some representative microstructures associated with different positions, that is, different cooling rates $(\dot{T})$ along the length of the DS 5052 alloys castings. Fig. 5 shows in mode details not only the side by side configurations of the prolonged grains but also fully dendritic morphologies. This

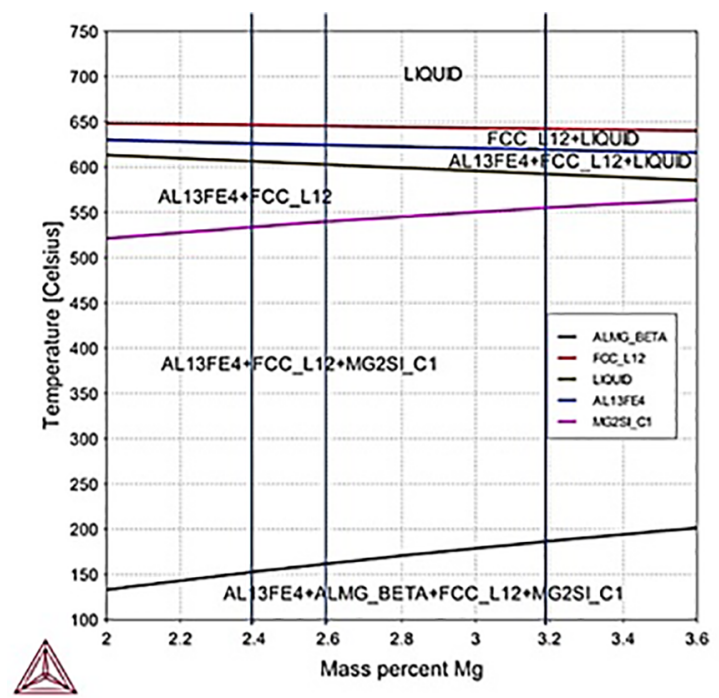

Figure 4. Partial pseudo-binary Al-0.3wt \%Fe-0.1wt \%Si-xwt $\% \mathrm{Mg}$ phase diagram. happens for the three examined alloys regardless of the level of the cooling rate associated with a certain microstructure. The dendritic structure of a certain alloy is characterized by fine to large length-scales depending on the examined position along the length of the casting body.

Experimental cooling curves related to the thermocouples within each alloy casting, during solidification of the $5052-2.4 \mathrm{wt} \% \mathrm{Mg}, 5052-2.6 \mathrm{wt} \% \mathrm{Mg}$ and $5052-3.2 \mathrm{wt} \% \mathrm{Mg}$ alloys, are shown in Fig. 6.

Cooling rate $(\mathrm{T})$ and growth velocity $\left(\mathrm{V}_{\mathrm{L}}\right)$ experimental values have been calculated from the thermal profiles shown in Fig. 6. The determination of $\dot{T}$ as a function of position $(\mathrm{P})$ in the casting was carried out by computing the time-derivative of each cooling curve (dT/dt) right after the passage of the liquidus isotherm by the thermocouples. This means that depending on the position referred in the DS casting the sample examined refer either to slow or fast cooling conditions. Plots of position (P), from the metal $/$ mold interface, with the corresponding times $\left(\mathrm{t}_{\mathrm{L}}\right)$ of the liquidus fronts passing by each thermocouple were generated. Timederivatives of these generated functions permitted to calculate the growth velocity associated with the rate of displacement of the liquidus isotherm $\left(\mathrm{V}_{\mathrm{L}}\right)$. The experimental values of $\mathrm{V}_{\mathrm{L}}$ are shown in Fig. 7(a).

The experimental trends found for growth velocity show lower values for the alloy containing less $\mathrm{Mg}$, which is mainly
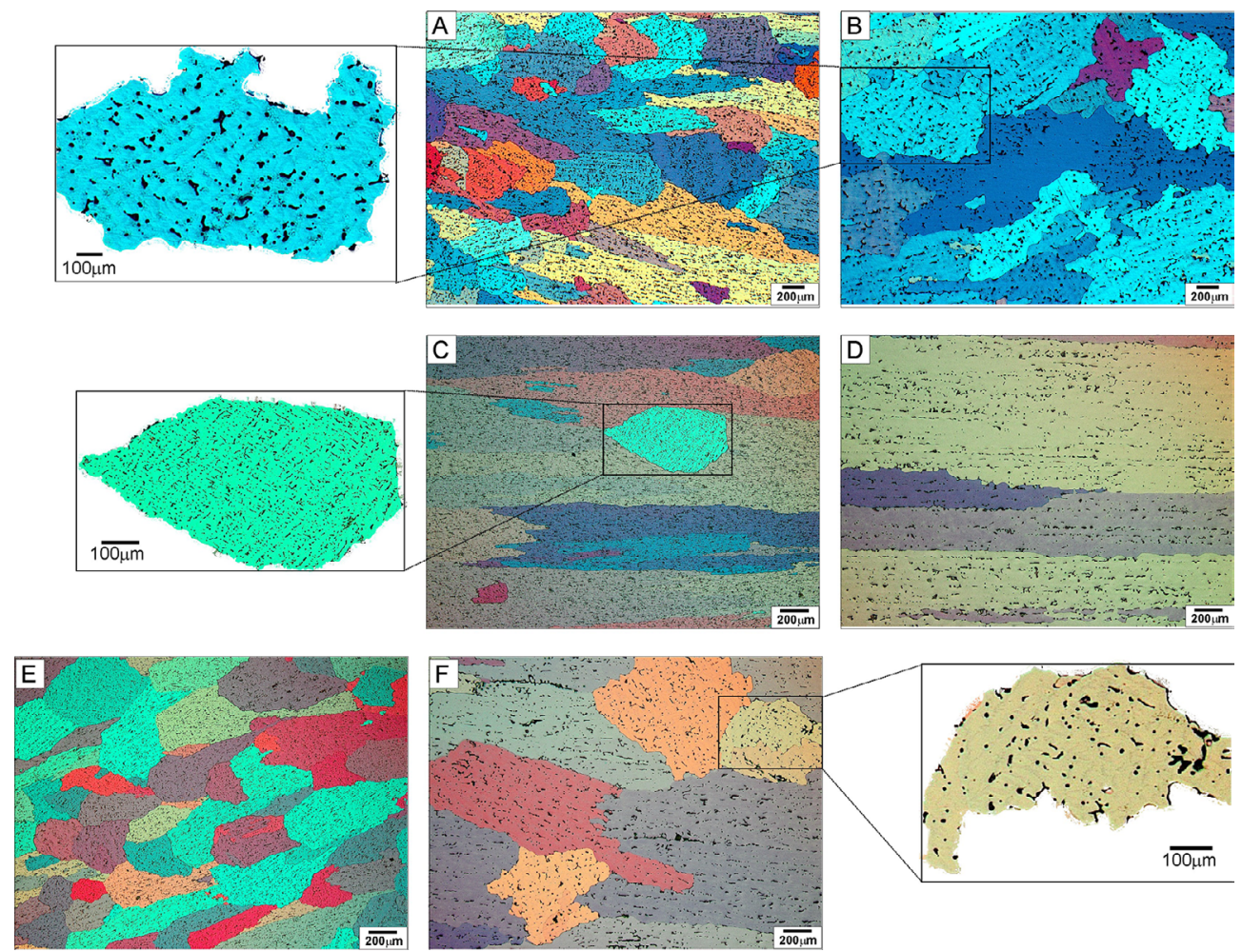

Figure 5. Polarized light optical as-cast microstructures of the directionally solidified 5052 aluminum alloys. These microstructures represent two levels of cooling regimes characterizing each composition: (A, B) $5052-2.4 \mathrm{wt} . \% \mathrm{Mg}$ (A: $7.0 \mathrm{~K} / \mathrm{s}$ and B: $0.4 \mathrm{~K} / \mathrm{s}),(\mathrm{C}, \mathrm{D}) 5052-2.6 \mathrm{wt} . \% \mathrm{Mg}(\mathrm{C}: 28.8 \mathrm{~K} / \mathrm{s}$ and D: $1.0 \mathrm{~K} / \mathrm{s})$ and $(\mathrm{E}, \mathrm{F}) 5052-3.2 \mathrm{wt} . \% \mathrm{Mg}(\mathrm{E}$ : $14.5 \mathrm{~K} / \mathrm{s}$ and F: $1.3 \mathrm{~K} / \mathrm{s}$ ) alloys. Typical dendritic arrays can be seen within the extracted grains either at the left or at right figure sides. 

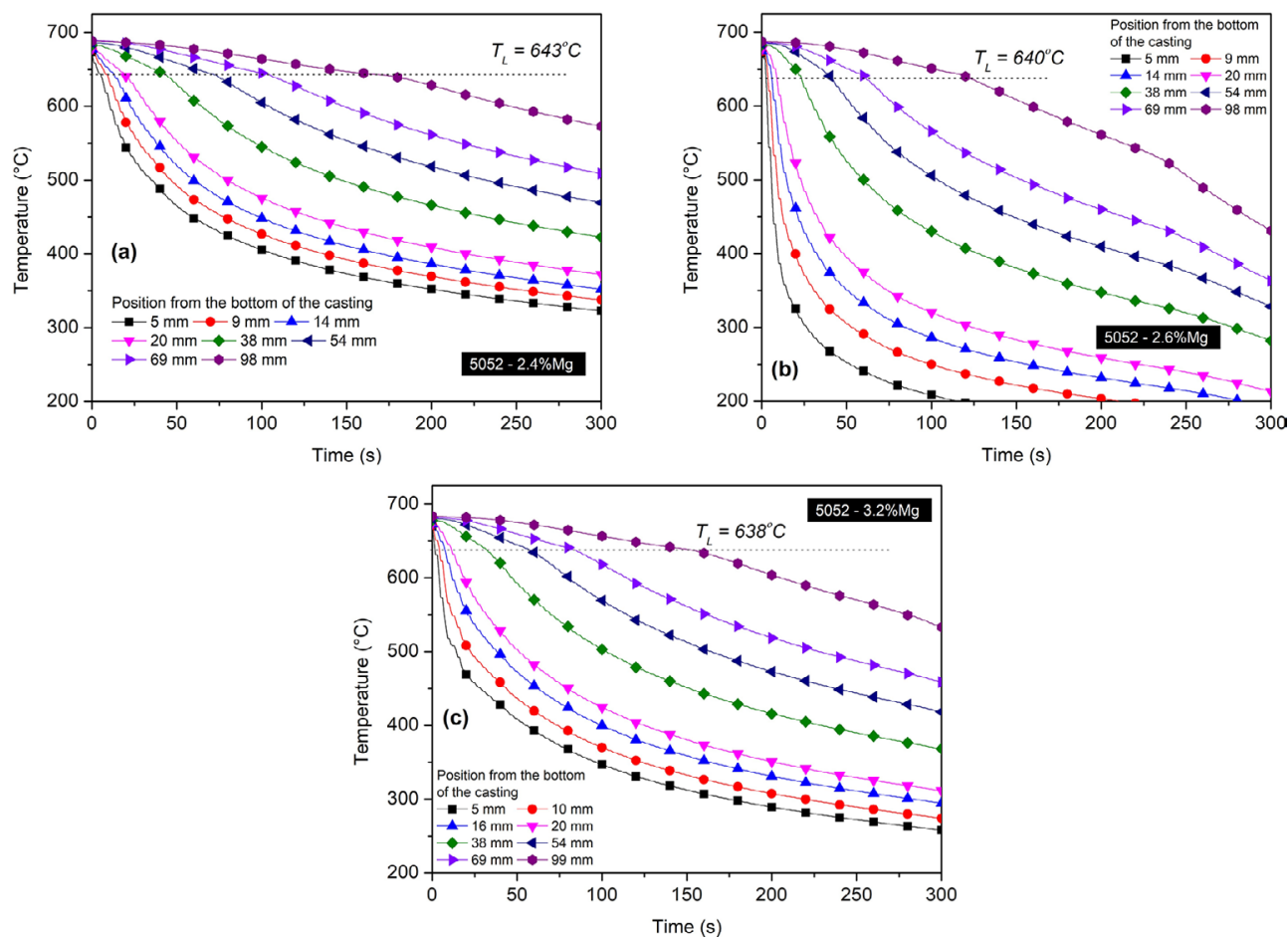

Figure 6. Thermal profiles acquired during transient directional solidification of the (a) $5052-2.4 \mathrm{wt} \% \mathrm{Mg}$, (b) $5052-2.6 \mathrm{wt} \% \mathrm{Mg}$ and (c) $5052-3.2 \mathrm{wt} \% \mathrm{Mg}$ alloys.

noticed for the positions near the base of the casting, as can be observed in Fig. 7(a). The freezing intervals $(\Delta T)$ of the three alloys are quite close. According to the experimental cooling curves, these intervals are $32^{\circ} \mathrm{C}, 33^{\circ} \mathrm{C}$ and $33^{\circ} \mathrm{C}$ for the $5052-2.4 \mathrm{wt} \% \mathrm{Mg}, 5052-2.6 \mathrm{wt} \% \mathrm{Mg}$ and $5052-3.2 \mathrm{wt} \% \mathrm{Mg}$ alloys, respectively. Therefore, the differences in growth velocity may not be explained by the $\Delta \mathrm{T}$. It appears that such differences in $\mathrm{V}_{\mathrm{L}}$ can be explained by fluidity variations as a function of $\mathrm{Mg}$ content. This is in agreement with the results of fluidity tests provided by Kim et al. ${ }^{23}$, since fluidity is recognized to have impact on the heat transfer efficiency between metal and mold during casting operations, which is translated by means of the solidification kinetics. These results of fluidity tests by Kim et al. ${ }^{23}$ demonstrated that pure Al solidifies with planar front, which permitted a larger length of fluidity to be obtained as compared to those of $\mathrm{Al}-\mathrm{Mg}$ alloys. The alloy containing $2.5 \mathrm{wt} \% \mathrm{Mg}$ develops a mushy zone and, as a consequence, decreases the flow length. Higher Mg-contents promotes a gain in the flow length, reversing the established trend starting from the pure Al. In view of the chemistries evaluated in the present investigation, it seems that increase in $\mathrm{Mg}$ content causes an increase in fluidity and consequently in the alloy/mold wettability. As a result, the growth velocity is inclined to increase for positions close to the casting cooled surface. With the progress of solidification, the increase in the solid thermal resistance with the increasingly thickness of the solid layer, makes $\mathrm{V}_{\mathrm{L}}$ to progressively decrease.
A behavior reversed according to the tested compositions could be observed for the variations of the local solidification time as compared to those of $\mathrm{V}_{\mathrm{L}}$ as can be seen in Fig. 7(b). In this plot, higher local solidification times belong to the alloy with minor $\mathrm{Mg}$ content. The local solidification time has been calculated as the difference spent in a certain point in the casting between the transit times of the liquidus and the solidus isotherms.

\subsection{Scaling laws and hardness vs. $\lambda_{2}$}

Figs. 8(a) and Fig. 8(b) present the mean experimental values, along with the standard variation, of the secondary $\left(\lambda_{2}\right)$ dendritic spacings as a function of the growth velocity and the local solidification time, respectively. Power function relationships demonstrated to be representative of the microstructural scaling laws. The $\lambda_{2}$ values were measured from the microstructures of the DS castings. Analyzing the experimental tendencies and lines in the graphs of Figs. $8(a-b)$, it is worth noting that the increase in Mg-content of a 5052 alloy had impact on $\lambda_{2}$. This is clear when comparing the results for the $5052-2.4 \mathrm{wt} \% \mathrm{Mg}$ alloy with the other two chemistries, that is, the $5052-2.6 \mathrm{wt} \% \mathrm{Mg}$ and $5052-3.2 \mathrm{wt} \% \mathrm{Mg}$ alloys. A -1.1 power law characterizes the experimental variations of $\lambda_{2}$ with $V_{L}$ while a $1 / 3$ exponent is capable to represent the variations found for $\lambda_{2}$ with $t_{\mathrm{SL}}$. A -1.1 exponent was also shown to be appropriate in the power function equation relating $\lambda_{2}$ to the $\mathrm{V}_{\mathrm{L}}$ obtained for the ternary Al-1.2wt\%Mg-1.5wt.\%Fe and Al-7.0wt\%Mg- 

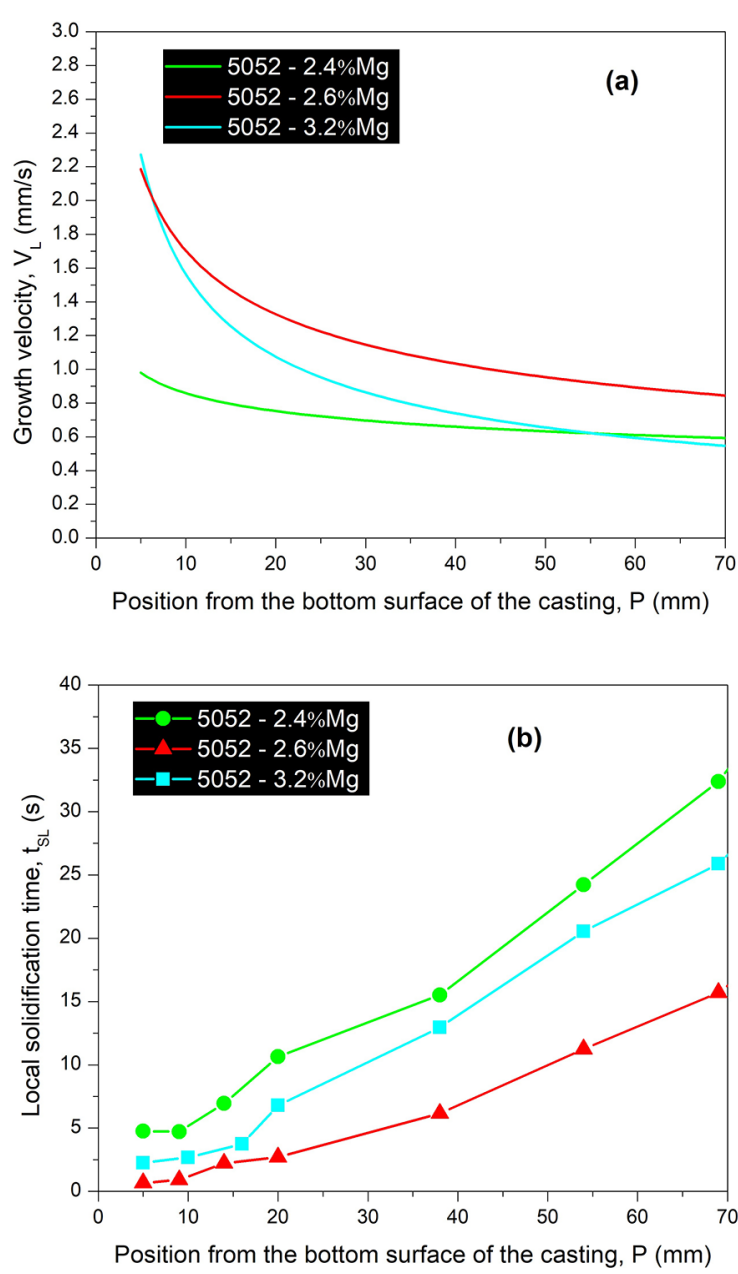

Figure 7. Plots for the DS 5052 aluminum alloys castings corresponding to (a) growth velocity $\left(\mathrm{V}_{\mathrm{L}}\right)$ and (b) local solidification time $\left(\mathrm{t}_{\mathrm{SL}}\right)$ as a function of position $(\mathrm{P})$ from the water-cooled surface.

$1.5 \mathrm{wt} \% \mathrm{Fe}$ alloys ${ }^{17}$. In this case, the single power function $\lambda_{2}=22\left(\mathrm{~V}_{\mathrm{L}}\right)^{-1.1}$ has been proposed for both alloys.

According to the results showed by Liu and Kang ${ }^{24}$, increasing in $\mathrm{Mg}$ content allows the eutectic fraction to be increased. These authors evaluated the influence of composition and cooling rate on solidification and segregation of binary Al-Mg alloys, with magnesium content ranging between 2.46 wt.\% and 11.07 wt.\%. Higher eutectic fraction is a result of higher segregation of $\mathrm{Mg}$ into the liquid immediately ahead of the solidification front. It appears that in the case of the three examined commercial 5052 aluminum alloys, higher $\mathrm{Mg}$ content in the interdendritic liquid was capable to generate more instability of the front initially formed by dendrite primary trunks. As a consequence, secondary branches are facilitated to initiate in a higher rate from the primary stems due to the local enriched $\mathrm{Mg}$ content. Oppositely, the alloy containing $2.4 \mathrm{wt} . \% \mathrm{Mg}$ do not permit such high rate of secondary branches. This could explain why for same $\mathrm{V}_{\mathrm{L}}$ and $\mathrm{t}_{\mathrm{SL}}$, the $\lambda_{2}$ for the $5052-2.4 \mathrm{wt} \% \mathrm{Mg}$ alloy is higher than those for the $5052-2.6$ and $3.2 \mathrm{wt} \% \mathrm{Mg}$ alloys.

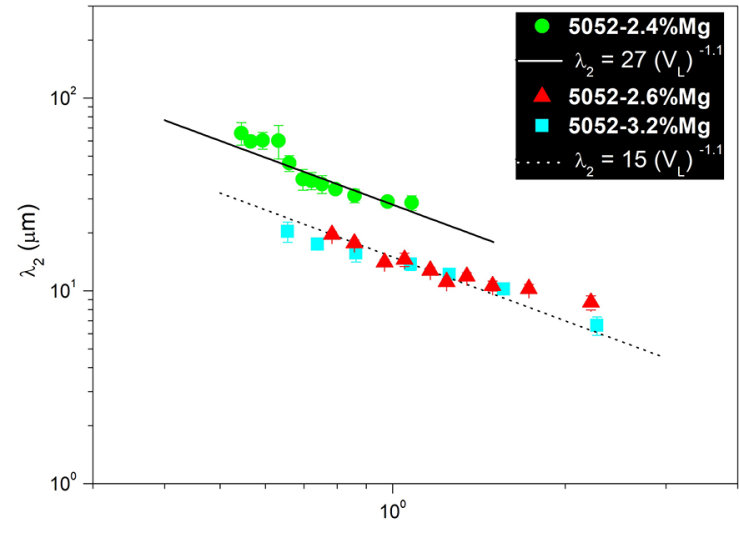

Growth velocity, $V_{L}(\mathrm{~mm} / \mathrm{s})$

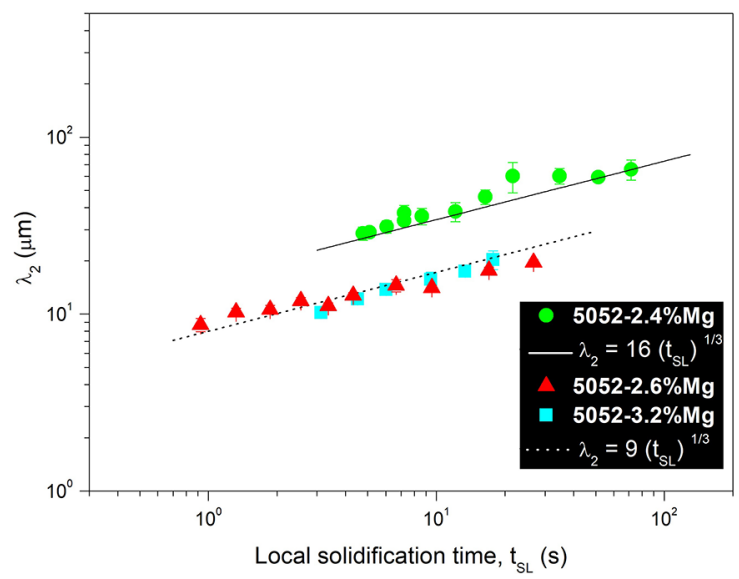

Figure 8. Experimental scatters of $\lambda_{2}$ and experimental growth laws derived for the $5052-2.4 \mathrm{wt} \% \mathrm{Mg}, 5052-2.6 \mathrm{wt} \% \mathrm{Mg}$ and $5052-3.2 \mathrm{wt} \% \mathrm{Mg}$ alloys.

Relationships between the cube root of local solidification time, $\mathrm{t}_{\mathrm{SL}}{ }^{1 / 3}$, and $\lambda_{2}$ characterize the DS commercial 5052 aluminum alloys ingots as shown in Fig. 8(b). Despite being predominantly investigated for binary $\mathrm{Al}$ alloys ${ }^{25,26}$, the specialized literature points to this type of correlation. Correlations as those employed here may provide a fairly accurate estimation of $\lambda_{2}$ for $\mathrm{Al}$ alloys over a wide range of solidification times, $0.1 \mathrm{~s}<\mathrm{t}_{\mathrm{SL}}<10^{7} \mathrm{~s}{ }^{27}$.

The average Brinell hardness variation against the secondary dendritic spacing is shown in Fig. 9 for the commercial 5052 alloys. According to Campbell ${ }^{28}$, the DAS is often the parameter appearing as the most important structural length parameter in dendritic arrangements. This is because the secondary dendritic spacing, $\lambda_{2}$, is more representative of the distribution level of the second phases formed during solidification.

A tendency of increasing hardness is noted with decreasing $\lambda_{2}$. Such trend is owing to the growth of reinforcing Fecontaining and $\mathrm{Mg}$-containing intermetallic particles within the interdendritic regions. Lower $\lambda_{2}$ may result in more homogeneously distribution of reinforcing phases throughout 


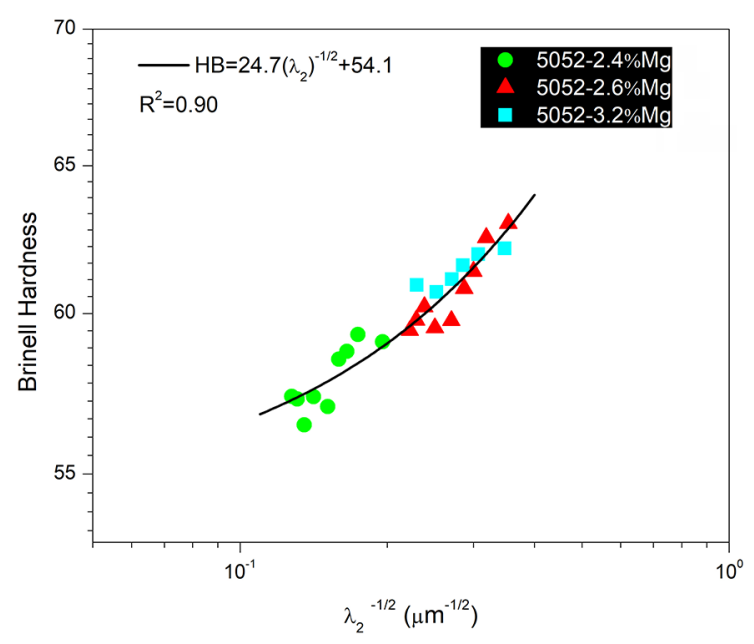

Figure 9. Brinell hardness as a function of the secondary dendritic spacing of the directionally solidified 5052 aluminum alloys.

the microstructure. As such, hardness increases. A Hall-Petch type correlation adjusts thoroughly.

Despite non-coincidence of points with same $\lambda_{2}{ }^{-1 / 2}$ if the $5052-2.4 \mathrm{wt} . \% \mathrm{Mg}$ alloy is compared to the other two alloys, a hardness $\times \lambda_{2}^{-1 / 2}$ point on the plot of $59.1 \mathrm{HB} \times 0.20 \mu \mathrm{m}^{-1 / 2}$ can be noted for the $5052-2.4 \mathrm{wt} \% \mathrm{Mg}$ alloy whereas a point of $59.4 \mathrm{HB} \times 0.21 \mu^{-1 / 2}$ refers to the $5052-2.6 \mathrm{wt} \% \mathrm{Mg}$ alloy. In view of the observed deviations-from-average of $\lambda_{2}$ in Fig. 8 about $5-10 \%$, and very close hardnesses in these points, it can be sustained that hardness is roughly the same. This kind of analysis contributes to the single trend representing the variations of hardness with $\lambda_{2}$ for the three DS 5052 aluminum alloys castings.

\section{Conclusions}

Transient directional solidification experiments were carried out with three commercial 5052 alloys containing 2.4wt.\%, 2.6wt.\% and 3.2wt.\% Mg with a view to determining correlations between growth velocity, $\mathrm{V}_{\mathrm{L}}$; local solidification time, $\mathrm{t}_{\mathrm{SL}}$, and secondary dendritic arm spacing, $\lambda_{2}$, as well as the effect of length scale of the dendritic pattern, represented by $\lambda_{2}$, on the Brinnell hardness (HB). The highest value of $\mathrm{V}_{\mathrm{L}}$ was shown to be associated with to a position close to the cooled surface of the casting for the alloy having highest $\mathrm{Mg}$ content. This has been attributed to the increase in fluidity, caused by the increase in the alloy $\mathrm{Mg}$ content. Experimental growth expressions relating $\lambda_{2}$ to both $\mathrm{V}_{\mathrm{L}}$ and $\mathrm{t}_{\mathrm{SL}}$ have been derived:

$$
\begin{aligned}
& 5052 \text { alloy }-2.4 w t \% M g: \\
& \quad \lambda_{2}=27\left(V_{L}\right)^{-1.1} ; \lambda_{2}=16\left(t_{S L}\right)^{1 / 3}
\end{aligned}
$$

$$
\begin{aligned}
& 5052 \text { alloy }-2.6 w t \% M g \text { and } 3.2 w t \% M g: \\
& \lambda_{2}=15\left(V_{L}\right)^{-1.1} ; \lambda_{2}=9\left(t_{S L}\right)^{1 / 3}
\end{aligned}
$$

$$
\lambda_{2}[\mu m] ; V_{L}[m m / s] \text { and } t_{S L}[s]
$$

That is, a more refined dendritic microstructure is associated with the increase in the alloy $\mathrm{Mg}$ content. The Brinell hardness was shown to decrease with the increase in $\lambda_{2}$, namely from bottom to the top of the directionally solidified castings. A Hall-Petch type correlation between HB and $\lambda_{2}$ has been proposed, which was shown to represent a trend encompassing the three examined 5052 aluminum alloys. i.e:

$$
H B=2.47\left(\lambda_{2}\right)^{-1 / 2}+54.1
$$

\section{Acknowledgements}

The authors acknowledge the financial supports provided by FAPESP (São Paulo Research Foundation, Brazil: grant number 2017/12741-6), National Council for Scientific and Technological Development - CNPq and CAPES.

\section{References}

1. Bray JW. ASM Metals Handbook. Volume 2. 10th ed. Materials Park: ASM International; 1976.

2. D'Antuono DS, Gaies J, Golumbfskie W, Taheri ML. Grain boundary misorientation dependence of $\beta$ phase precipitation in an Al-Mg alloy. Scripta Materialia. 2014;76:81-84.

3. Davis JR, ed. Corrosion of aluminum and aluminum alloys. Materials Park: ASM International; 1999.

4. ASM International; Metals Handbook Committee. ASM Handbook, Volume 2: Properties and Selection: Nonferrous Alloys and SpecialPurpose Materials. 2nd ed. Materials Park: ASM International; 1992.

5. Totten GE, Mackenzie DS. Handbook of Aluminum: Physical Metallurgy and Properties. Volume 1. New York: Marcel Deckker; 2003.

6. Eskin DG. Physical Metallurgy of Direct Chill Casting of Aluminum Alloys. Boca Raton: CRC Press; 2008. 328 p.

7. Belov NA, Eskin DG, Aksenov AA. Multicomponent Phase Diagrams: Application for Commercial Aluminum Alloys. Amsterdam: Elsevier Science; 2005. 424 p.

8. Moshwan EA, Yusof F, Hasan MA, Rahmat SM. Effect of tool rotational speed on force generation, microstructure and mechanical properties of friction stir welded Al-Mg-Cr-Mn (AA 5052-O) alloy. Materials \& Design (1980-2015). 2015;65(Pt A):118-128.

9. Yun M, Lokyer S, Hunt JD. Twin roll casting of aluminium alloys. Materials Science and Engineering: A. 2000;280(1):116-123.

10. Cruz KS, Meza ES, Fernandes FAP, Quaresma JMV, Casteletti LC, Garcia A. Dendritic Arm Spacing Affecting Mechanical Properties and Wear Behavior of Al-Sn and Al-Si Alloys Directionally Solidified under Unsteady-State Conditions. Metallurgical and Materials Transactions A . 2010;41(4):972984. 
11. Rosa D, Spinelli JE, Garcia A. Tertiary dendrite arm spacing during downward transient solidification of $\mathrm{Al} \mathrm{Cu}$ and $\mathrm{Al} \mathrm{Si}$ alloys. Materials Letters. 2006;60(15):1871-1874.

12. ASTM International. ASTM B209M-10-Standard Specification for Aluminum and Aluminum-Alloy Sheet and Plate (Metric). West Conshohocken: ASTM International; 2010.

13. Man T, Zhang L, Xiang Z, Wang W, Huang M, Wang E. Improvement of Microstructure and Wear Property of Al-Bi Alloys by Nd Addition. JOM. 2018;70(7):1344-1348.

14. Dinnis CM, Taylor JA Dahle AK. Iron-related porosity in Al$\mathrm{Si}-(\mathrm{Cu})$ foundry alloys. Materials Science and Engineering: $A$. 2006;425(1-2):286-296.

15. Grosselle F, Timelli G, Bonollo F, Molina R. Correlation between microstructure and mechanical properties of Al-Si diecast engine blocks. Metallurgical Science and Technology. 2009;27(2):2-10.

16. Rodrigues JRP, Souza TXA, Andrade RB, Santos RG, Mello MLNM. Overheating influence on solidification - thermal variables and microstructure formation of aluminium alloy. Rem: Revista da Escola de Minas. 2009;62(4):481-486.

17. Gomes LF, Silva BL, Garcia A, Spinelli JE. Dendritic Growth, Solidification Thermal Parameters, and Mg Content Affecting the Tensile Properties of Al-Mg-1.5 Wt Pct Fe Alloys. Metallurgical and Materials Transactions A. 2017;48(4):1841-1855.

18. Brito C, Reinhart G, Nguyen-Thi H, Mangelinck-Noël N, Cheung N, Spinelli JE, et al. High cooling rate cells, dendrites, microstructural spacings and microhardness in a directionally solidified Al-Mg-Si alloy. Journal of Alloys and Compounds. 2015;636:145-149.

19. ASM Handbook Committee. ASM Handbook Volume 2: Properties and Selection: Nonferrous Alloys and Special-Purpose Materials. Materials Park: ASM International; 1990. DOI: 10.1361/ asmhba0001060
20. Reyes RV, Bello TS, Kakitani R, Costa TA, Garcia A, Cheung $\mathrm{N}$, et al. Tensile properties and related microstructural aspects of hypereutectic Al-Si alloys directionally solidified under different melt superheats and transient heat flow conditions. Materials Science and Engineering: A. 2017;685:235-243.

21. Bertelli F, Freitas ES, Cheung N, Arenas MA, Conde A, Damborenea J, et al. Microstructure, tensile properties and wear resistance correlations on directionally solidified Al-Sn-(Cu; Si) alloys. Journal of Alloys and Compounds. 2017;695:3621-3631.

22. Gündüz M, Çadirli E. Directional solidification of aluminiumcopper alloys. Materials Science and Engineering: A. 2002;327(2):167-185.

23. Kim NS, Ha SH, Yoon YO, Yeom GY, Lim HK, Kim SK. Effect of $\mathrm{Mg}$ Contents on Fluidity of Al-xMg Alloys. In: Sadler BA, ed. Light Metals. Cham: Springer; 2013. p. 453-456.

24. Liu YL, Kang SB. Solidification and segregation of Al-Mg alloys and influence of alloy composition and cooling rate. Materials Science and Technology. 1997;13(4):331-336.

25. Kirkwood DH. A Simple model for dendrite arm coarsening during solidification. Materials Science and Engineering. 1985;73:L1-L4.

26. Rocha OL, Siqueira CA, Garcia A. Cellular/dendritic transition during unsteady-state unidirectional solidification of $\mathrm{Sn}-\mathrm{Pb}$ alloys. Materials Science Engineering: A. 2003;347(1-2):5969.

27. Dantzig JA, Rappaz M. Solidification. 2nd ed. Collection: Materials. Lausanne: EPFL Press; 2016.

28. Campbell J. Castings. Oxford: Butterworth-Heinemann; 2003. 